\title{
Anesthesia practice in cesarean delivery in tertiary care hospital: a retrospective observational study
}

\author{
Sigdel Rohini ${ }^{1}$, Lama Maya ${ }^{1}$, Gurung Sanish ${ }^{1}$, Timilsina Sushil ${ }^{1}$ \\ ${ }^{1}$ Department of Anesthesiology, Pokhara Academy of Health Sciences, Western Regional Hospital
}

\section{Corresponding Author}

Dr. Rohini Sigdel

Chief Consultant Anesthesiologist

Department of Anesthesiology

Pokhara Academy of Health Sciences, Western Regional Hospital, Pokhara Nepal

Email: rohini88999@gmail.com Article received : February 20, 2018

Article accepted : March 9, 2018

\begin{abstract}
Background: Regional anesthesia is being utilized as the preferred anesthetic technique for cesarean delivery worldwide. This study was performed to review cesarean delivery anesthetic practice in our institute which represents a tertiary care regional hospital. Methods: Data was collected regarding the number of cesarean delivery performed during the period of six months from January 2017 to June 2017 at Western Regional Hospital. Number of elective versus emergency cesarean delivery, mode of anesthesia and the reason for general anesthesia and complications was recorded. Results: The number of cesarean delivery was found to be $1174(26.41 \%)$ of total deliveries during the study period. Out of which, $64.82 \%$ were for emergency indication and $35.18 \%$ were elective cesarean delivery. Spinal anesthesia was utilized in $99.03 \%$ of elective cesarean section and $97.63 \%$ of emergency cesarean section. The percentage of cases performed under general anesthesia was $1.87 \%$. Reasons for general anesthesia included inadequate subarachnoid block, fetal malpresentation, eclampsia and maternal comorbidities. Complications related to general anesthesia like failed intubation, airway difficulty related to general anesthesia and anesthesia related mortality was not encountered. Conclusion: Spinal anesthesia is utilized widely and safely in obstetric practice at our hospital. Use of labour epidural analgesia should be introduced and encouraged in our setting to minimize the side effects of single shot spinal anesthesia and to avoid general anesthesia when indicated.
\end{abstract}

Keywords: Cesarean delivery; general anesthesia; regional anesthesia; spinal anesthesia

\section{INTRODUCTION}

According to the World Health Organization (WHO), cesarean section rates higher than $10 \%$ are not associated with reduction in maternal and newborn mortality rates. ${ }^{1}$ Newer techniques and drugs that have evolved in obstetric anesthesia management and maternal requests have increased the cesarean section rates in the recent years. The use of neuraxial techniques for cesarean section has significantly decreased the obstetric mortality. ${ }^{2}$ Neuraxial techniques should be considered in preference to general anesthesia for most cesarean deliveries. ${ }^{3}$ The aim of this study was to determine current obstetric anesthesia practice at a tertiary care hospital.

\section{MATERIALS AND METHODS}

This retrospective observational study was carried out after the permission from the authority of Western Regional Hospital. It involved all the pregnant women undergoing cesarean delivery for elective as well as emergency indication in our hospital for the period of six months from January to June 2017. The anesthesia record at our institution was examined to determine the number of cesarean deliveries, both elective and emergency and the type of anesthesia provided. The number of patients in different age group and the reason for general anesthesia and complications related to it was also recorded. The data was expressed in simple percentage and figure using Microsoft Office 2016. 
RESULTS

Table 1: Age distribution and total number of cesarean section $(\mathbf{N})$

\begin{tabular}{ccc}
\hline & $\mathrm{N}=1174$ \\
\hline Age (years) & $\mathbf{N}$ & Percentage \\
\hline$<20$ & 73 & $6.2 \%$ \\
$21-30$ & 928 & $79.05 \%$ \\
$31-40$ & 165 & $14.05 \%$ \\
$>40$ & 8 & $0.68 \%$
\end{tabular}

The total number of cesarean section during the period of six month was $1174(26.41 \%)$. Most of the parturients undergoing cesarean delivery were aged 20-30 years. (Table 1)

Table 2: Table showing total number of cesarean section

\begin{tabular}{ccc}
\hline Cesarean Section & $\mathbf{n = 1 1 7 4}$ & Percentage \\
\hline Elective: & 413 & $35.18 \%$ \\
SA & 409 & $99.03 \%$ \\
GA & 4 & $0.97 \%$ \\
\hline Emergency: & 761 & $64.82 \%$ \\
SA & 743 & $97.63 \%$ \\
GA & 18 & $2.37 \%$ \\
\hline
\end{tabular}

The total number of emergency cesarean section was greater than elective cesarean section. (Table 2) $1.87 \%$ of the total cesarean sections were performed under general anesthesia.

Table 3. Reasons for general anesthesia during cesarean section

\begin{tabular}{lccc}
\hline Cause & N & Elective & Emergency \\
\hline 1. Inadequate block & 7 & 2 & 5 \\
2. Eclampsia & 4 & - & 4 \\
3. APH (Ante-Partum & 3 & - & 3 \\
Hemorrhage) & & & \\
4. Malpresentation & 5 & - & 5 \\
5. Fetal distress & 1 & - & 1 \\
6. Maternal comorbidities & 2 & 2 & - \\
Total & 22 & 4 & 18 \\
\hline
\end{tabular}

Most common reason for general anesthesia was inadequate subarachnoid block followed by fetal malpresentation, eclampsia, maternal comorbidities and fetal distress. (Table 3)Complications like failed intubation, airway difficulty related to general anesthesia and anesthesia related mortality was not encountered during cesarean sections performed under general anesthesia.

\section{DISCUSSION}

The rate of cesarean delivery is increasing in the recent years. The advancement in anesthetic as well as obstetric management, awareness and patient request might have substantially increased the rate of cesarean delivery. However, cesarean sections can cause significant and sometimes permanent complications, disability or death particularly in settings that lack the facilities or capacity to conduct safe surgery and treat surgical complications. ${ }^{1}$

The data of our study reveals the rate of cesarean delivery at our hospital during the six months study period was $26.41 \%$, which is similar to our previous annual rate ranging from 22 to $25 \%$ in the past three fiscal years. With more than 8000 annual delivery, ${ }^{4}$ our rate is comparable to overall cesarean rate in the units with more than 4500 annual delivery in the United Kingdom and the United States of America where cesarean delivery accounted for $23.65 \%$ to $31.51 \%$ of the annual total ranging from 8543 to 10091 deliveries. ${ }^{5,6}$

The percentage of elective cesarean section was $35.18 \%$ whereas $64.82 \%$ were emergency cesarean section. However, the emergency cesarean sections were not categorized according to urgency as classified by the Royal College of Obstretician and Gynaecologists and the Royal College of Anaesthetists. ${ }^{7}$ Majority of cesarean section, both elective and emergency, were performed under single shot spinal anesthesia. A survey of perioperative and postoperative anesthetic practices for cesarean delivery done by Leinani Aiono-Le Tagaloa et al. also revealed single shot spinal anesthesia as the preferred regional technique for cesarean delivery among greater than $85 \%$ of the anesthesiologists. ${ }^{8}$ Single shot spinal anesthesia is the preferred method of regional technique for both emergency and elective cesarean at our institution.

The percentage of cases performed under general anesthesia was $1.87 \%$ which is slightly higher than the finding in a retrospective analysis of general anesthesia for cesarean delivery at a tertiary care hospital from 2000 to 2005 , where they had $0.5 \%$ to $1 \%$ of cesarean delivery performed under general anesthesia. ${ }^{6}$ The most common reason for general anesthesia was inadequate subarachnoid block which accounted for about 32\% of the cases performed under general anesthesia. This is quite high compared to less than $4 \%$ in some other 
studies. ${ }^{6}$ Such differences may be due to the expertise of the performing anesthesiologist and where one is in his learning phase. However, the number of years of practicing experience was not mentioned in their study nor in ours.

General anesthesia has been utilized for cesarean section in order to minimize the delay in emergency cases with fetal or maternal compromise. Kinsella et al. have reported that the use of modified spinal anesthesia so called rapid sequence spinal anesthesia can reduce the decision to delivery interval in even category 1 patients. ${ }^{9}$ This technique can be applied in units with sufficient number of obstetric anesthesiologists. Change in anesthesia practice has been shown in studies and survey towards neuraxial technique rather than general anesthesia compared to the past. ${ }^{10}$

Epidural labour analgesia is still not so popular in many of the developed countries. The idea of an epidural catheter being useful for urgent cesarean section has not been well accepted. ${ }^{11}$ However, many Systematic and Cochrane reviews have revealed the increased risk of instrumental delivery but no increase in the rate of cesarean delivery in patients receiving labour epidural analgesia. ${ }^{12,13}$ Few randomized trials comparing patient controlled epidural analgesia versus intravenous analgesia for pain relief in labour did not show significant increase in obstetric intervention in epidural group. ${ }^{14} \mathrm{~A}$ randomized trial conducted by Gonen et al. has even demonstrated the use of early labour epidural without increase in the rate of cesarean delivery and instrumental delivery compared to those with late epidural placements. ${ }^{15}$ The issue of time efficiency, costs, charge, complications and insufficient number of obstetric anesthesiologists are the reasons for non-application of labour epidural analgesia in our setup. The demand of labour epidural analgesia and its application in emergency cesarean section may be recognized in future. So far, failed intubation, airway difficulty related to general anesthesia and anesthesia related mortality was not encountered during the study period.

\section{CONCLUSION}

Spinal anesthesia is utilized widely and safely in obstetric practice at our hospital. Use of labour epidural analgesia should be introduced and encouraged in our setting to minimize the side effects of single shot spinal anesthesia and to avoid general anesthesia when indicated. Anesthesiologists should well understand the operative urgency and apply optimal anesthesia method for each patient taking into account the safety of both mother and fetus.

\section{REFERENCES}

1. WHO Statement on caesarean section rates. Reprod Health Matters. 2015 May;23(45):149-50. Rollins M, Lucero J. Overview of anesthetic considerations for Cesarean delivery. $\mathrm{Br}$ Med Bull. 2012;101:105-25.

2. Practice guidelines for obstetric anesthesia: an updated report by the American Society of Anesthesiologists Task Force on Obstetric Anesthesia. Anesthesiology. 2007 Apr;106(4):843-63.

3. Government of Nepal, Ministry of Health, Pokhara Academy of Health Sciences WRH. Annual Report 2072/2073. 2017:1-33.

4. Kinsella SM, Walton B, Sashidharan R, Draycott T. Category-1 caesarean section: a survey of anaesthetic and peri-operative management in the UK. Anaesthesia. 2010 Apr;65(4):362-8.

5. Palanisamy A, Mitani AA, Tsen LC. General anesthesia for cesarean delivery at a tertiary care hospital from 2000 to 2005 : a retrospective analysis and 10-year update. Int J Obstet Anesth. 2011 Jan;20(1):10-6.

6. Classification of urgency of caesarean section- A Classification of Urgency of Caesarean Section- A Continum of Risk. Good Pract No 11. 2010:1-4

7. Aiono-Le Tagaloa L, Butwick AJ, Carvalho B. A survey of perioperative and postoperative anesthetic practices for cesarean delivery. Anesthesiol Res Pract. 2009;2009:510642.

8. Kinsella SM, Girgirah K, Scrutton MJL. Rapid sequence spinal anaesthesia for category-1 urgency caesarean section: a case series. Anaesthesia. $2010 \mathrm{Jul} ; 65(7): 664-9$.

9. Stamer UM, Wiese R, Stuber F, Wulf H, Meuser T. Change in anaesthetic practice for Caesarean section in Germany. Acta Anaesthesiol Scand. 2005 Feb;49(2):170-6.

10. Sumikura H. Anesthetic management of urgent cesarean section. Hypertens Res Pregnancy. 2016;4(1):1-5.

11. Leighton BL, Halpern SH. The effects of epidural analgesia on labor, maternal, and neonatal outcomes: a systematic review. Am J Obstet Gynecol. 2002 May;186(5 Suppl Nature):S69-77.

12. Anim-Somuah M, Smyth R, Howell C. Epidural versus nonepidural or no analgesia in labour. Cochrane database Syst Rev. 2005 Oct;(4):CD000331.

13. Halpern SH, Muir H, Breen TW, Campbell DC, Barrett J, Liston $\mathrm{R}$, et al. A multicenter randomized controlled trial comparing patient-controlled epidural with intravenous analgesia for pain relief in labor. Anesth Analg. 2004 Nov;99(5):1532-8.

14. Ohel G, Gonen R, Vaida S, Barak S, Gaitini L. Early versus late initiation of epidural analgesia in labor: does it increase the risk of cesarean section? A randomized trial. Am J Obstet Gynecol. 2006 Mar;194(3):600-5. 